BARROS, F.M. et al. Utilização de água residuária de suinocultura como fonte de nitrogênio para o solo. PUBVET, Londrina, V. 5, N. 33, Ed. 180, Art. 1212, 2011.

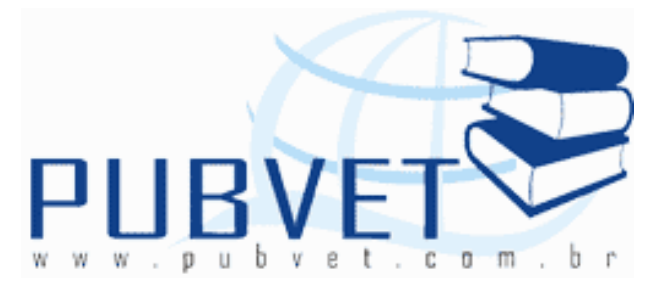

PUBVET, Publicações em Medicina Veterinária e Zootecnia.

\title{
Utilização de água residuária de suinocultura como fonte de nitrogênio para o solo
}

\author{
Flávia Mariani Barros ${ }^{1}$, Gabriel Domingos Carvalho ${ }^{2}$, Antônio Teixeira de \\ Matos $^{3}$, Mauro Aparecido Martinez ${ }^{3}$.
}

${ }^{1}$ Professora do Departamento de Estudos Básicos e Instrumentais Universidade Estadual do Sudoeste da Bahia (UESB), Itapetinga-BA. Autor para correspondência. E-mail: mariamariani@yahoo.com.br

${ }^{2}$ Professor do Curso de Medicina Veterinária do Instituto Federal Norte de Minas Gerais (IFNMG) - Campus Salinas, Salinas-MG.

${ }^{3}$ Professor do Departamento Engenharia Agrícola - Universidade Federal de Viçosa (DEA/UFV), Viçosa-MG.

\section{Resumo}

A disposição de águas residuárias provenientes de suinocultura no solo é uma atividade de reciclagem que viabiliza a utilização do potencial hídrico e dos nutrientes presentes nesses efluentes. Os dejetos de suínos têm grande potencial fertilizante, podendo favorecer tanto o produtor, que irá reduzir seus custos com a aplicação de fertilizantes, como ao meio ambiente, visto que esses estercos são altamente poluentes quando lançados diretamente em rios e lagos. O potencial poluente dos dejetos de suínos é muito superior ao de outras espécies animais e sua utilização como fertilizante orgânico pode também contribuir para a contaminação dos recursos hídricos e do solo se as 
BARROS, F.M. et al. Utilização de água residuária de suinocultura como fonte de nitrogênio para o solo. PUBVET, Londrina, V. 5, N. 33, Ed. 180, Art. 1212, 2011.

quantidades aplicadas forem superiores à capacidade do solo e das plantas em absorver os nutrientes presentes nesses resíduos. O nitrogênio é um dos principais nutrientes presentes nos dejetos de suínos. A mineralização do nitrogênio é influenciada, entre outros fatores, pela temperatura e pelo conteúdo de água do meio. Apesar de muitas tentativas de se desenvolver índices que possibilitem estimar de forma simples e eficiente a capacidade de mineralização de nitrogênio orgânico nos solos, não se tem obtido sucesso devido à complexidade de fatores que afetam a dinâmica deste elemento no solo. Embora sejam constatadas vantagens do uso de dejetos de suínos como fertilizante, pouco se sabe sobre a mineralização do nitrogênio orgânico presente neste dejeto. Neste contexto, este trabalho trata da utilização de dejetos de suínos como uma alternativa para fertilização do solo com ênfase na mineralização do nitrogênio orgânico.

Palavras-chave: água residuária, mineralização, nitrogênio, suinocultura.

\section{Use of residuary water form swine production as nitrogen source for the soil}

\section{Abstract}

The disposal of residuary water from swine production in soil is a recycling activity that makes possible the use of the hydric potential and the nutrients present in these effluents. The swine dejections have great fertilizing potential, being able to favor the producer that will reduce the costs with fertilizer application, as the environment, since these dejections are highly pollutant when launched directly in rivers and lakes. The pollutant potential of the swine dejections is very superior to other animal species and its use as organic fertilizing can also contribute for the contamination of the hydric resources and the soil if were applied amounts superior to the capacity of soil and plants in absorbing the nutrients present in these residues. The nitrogen is one of the main nutrients present in swine dejections. The mineralization of nitrogen is influenced, among others factors, for the temperature and the water content in 
BARROS, F.M. et al. Utilização de água residuária de suinocultura como fonte de nitrogênio para o solo. PUBVET, Londrina, V. 5, N. 33, Ed. 180, Art. 1212, 2011.

the medium. Although many attempts for the development of indices that make possible to esteem as a simple and efficient form the capacity of organic nitrogen mineralization in soil, success due has not been gotten by the complexity of factors that affect the dynamics of this element. Although advantages of the use of swine dejections as fertilizing are evidenced, is reduce the knowledge about the mineralization of organic nitrogen present in this dejection. In this context, this work deals with the use of swine dejections as an alternative for fertilization in soil with emphasis in the mineralization of organic nitrogen.

Keywords: mineralization, nitrogen, residuary water, swine production.

\section{INTRODUÇÃO}

O Brasil possui cerca de 37,5 milhões de cabeças de suínos, o que corresponde ao maior rebanho da América Latina, e o sexto do mundo (Anualpec, 2003). No Brasil, a suinocultura é praticada de diferentes formas nas distintas regiões do país. As regiões Sul, Sudeste e Centro-Oeste são responsáveis por $90 \%$ da produção brasileira, sendo uma atividade tecnificada que embora alcance índices de produtividade entre os melhores do mundo, vem apresentando problemas ambientais. A suinocultura predominante nas regiões Norte e Nordeste, é rústica e possui baixos índices de produtividade e sanidade. A geração de poluentes através das fezes, urina e gases demonstram que a suinocultura é uma atividade agropecuária de grande impacto ambiental (Nogueira e Silva, 2006).

Diversos autores ressaltam as vantagens da utilização de esterco na agricultura como o aumento do poder tampão, a intensificação das atividades microbianas e enzimáticas dos solos (Kiehl, 1985; Vieira, 1997), elevação dos teores de N, K, P, S, Ca e Mg do solo (Drumond, 2003) e aumento do teor de matéria seca em pastagem (Konzen, 2002).

O nitrogênio é um dos principais nutrientes presentes nos dejetos de suínos, sendo facilmente perdido por volatilização, lixiviação ou por desnitrificação (Bataglia et al., 1983). Nos países tropicais, a limitada 
BARROS, F.M. et al. Utilização de água residuária de suinocultura como fonte de nitrogênio para o solo. PUBVET, Londrina, V. 5, N. 33, Ed. 180, Art. 1212, 2011.

disponibilidade ou os altos custos dos fertilizantes nitrogenados têm levado à utilização de resíduos como fonte de nutrientes (Vanlauwe et al., 1997).

A dose de aplicação do resíduo pode ser determinada com base na concentração do nutriente presente em maior concentração que, normalmente, é o nitrogênio (Matos, 2004). O conhecimento das características do dejeto de suínos relacionadas à degradação microbiológica do nitrogênio orgânico pode contribuir para a previsão de seu comportamento no solo, permitindo definir referenciais úteis para o estabelecimento das doses máximas a serem aplicadas aos solos, em função do nitrogênio disponibilizado às plantas.

A concentração de nitrogênio mineralizado pode ser estimada com a utilização de modelos matemáticos, os quais quantificam essa concentração em função do tempo (Camargo et al., 1999). Devido aos inúmeros fatores que interferem na mineralização do nitrogênio, tem sido difícil encontrar características do solo que, indiretamente, possibilitem estimativas dos parâmetros dos modelos de mineralização.

Apesar de muitos esforços terem sido empreendidos na tentativa de desenvolver índices que possibilitem estimar, de forma simples e eficiente, a capacidade de mineralização de nitrogênio orgânico nos solos, não se tem obtido sucesso, dada a complexidade de fatores que afetam a dinâmica do elemento no solo (Santos, 2001). Tendo em vista a natureza dinâmica do nitrogênio e o grande número de fatores envolvidos no seu ciclo, predizer a mineralização do nitrogênio orgânico tem sido um desafio ao longo de décadas (Campbell et al., 1995; Alves et al., 1999).

Embora sejam constatadas vantagens do uso de dejetos de suínos como fertilizante do solo, pouco se sabe sobre a mineralização do nitrogênio orgânico presente neste dejeto. Neste contexto, este trabalho trata da utilização de dejetos de suínos como uma alternativa para fertilização do solo com ênfase na mineralização do nitrogênio orgânico. 
BARROS, F.M. et al. Utilização de água residuária de suinocultura como fonte de nitrogênio para o solo. PUBVET, Londrina, V. 5, N. 33, Ed. 180, Art. 1212, 2011.

\section{REVISÃO DE LITERATURA}

\section{A suinocultura e a produção de dejetos}

Os dejetos de suínos, até a década de 70, não constituíam maiores problemas para os criadores, pois a concentração de animais na propriedade era pequena. No entanto, com a intensificação da produção, para atender a demanda da população por carne suína, a maioria dos produtores passou a adotar o regime de confinamento e, como conseqüência, aumentou-se o volume de dejetos produzidos por unidade de área. A maior parte desses dejetos é lançada em cursos d'água, sem tratamento prévio, transformando-se em fonte poluidora dos mananciais e um fator de risco para a saúde animal e humana (Perdomo, 1995).

A geração de poluentes através das fezes, urina e gases demonstram que a suinocultura é uma atividade agropecuária de grande impacto ambiental (Nogueira e Silva, 2006). Bley Junior (1997) estima que uma granja com 300 matrizes, em ciclo completo, produz diariamente um volume de $60 \mathrm{~m} 3$ de águas residuárias, que contém uma tonelada de sólidos e que os suínos excretam $30 \%$ de sua alimentação em estado praticamente intacto. Segundo Brandão et al. (1999), cada suíno produz em média 10 litros de dejetos líquidos por dia. A quantidade total de dejetos produzidos pelos suínos varia com o estádio de desenvolvimento do animal, de 4,9 a $8,5 \%$ de seu peso, por dia, considerando a faixa dos 15 aos $100 \mathrm{~kg}$ de peso vivo. Entretanto, além das fezes, urina e restos de alimentos, a água desperdiçada em bebedouros e aquela utilizada na higienização das baias são componentes que aumentam ainda mais o volume de resíduos gerados, concorrendo para que a produção de dejetos líquidos seja da ordem de 8,85L/animal/dia (Marriel et al., 1987).

O potencial poluente dos dejetos de suínos é muito superior ao de outras espécies animais (Perdomo, 1995). A poluição causada pelos dejetos de suínos tende a crescer no Brasil devido, principalmente, ao crescimento do número de animais para atender ao consumo interno e às exportações de carne. O Brasil, no período de 1995-2001, expandiu sua produção em 55,9\%, sendo 
BARROS, F.M. et al. Utilização de água residuária de suinocultura como fonte de nitrogênio para o solo. PUBVET, Londrina, V. 5, N. 33, Ed. 180, Art. 1212, 2011.

responsável por $7,5 \%$ das exportações mundiais, passando a ser o quarto maior exportador de carne suína do mundo (Anualpec, 2003).

A água residuária de suinocultura (ARS) é rica em nitrogênio, fósforo e potássio. O fósforo e a alta demanda bioquímica de oxigênio (DBO) dos dejetos causam grandes impactos ao ecossistema aquático de superfície, sendo o fósforo responsável pelo processo de eutrofização e a alta DBO pela redução do oxigênio dissolvido na água. Já o nitrogênio oferece maior risco de contaminação das águas subterrâneas quando lixiviado no solo (Merten e Minella, 2002). Os dejetos produzidos pelo sistema de suinocultura quando lançados nos mananciais de água passam a gerar desequilíbrios ecológicos por causa da alta DBO, que é cerca de 260 vezes superior à do esgoto doméstico (Nogueira e Silva, 2006).

De acordo com Silva e Magalhães (2001), os sistemas de confinamento de suínos devem observar as seguintes premissas: (a) utilização dos dejetos e águas residuárias de suínos, atendendo a capacidade suporte do meio; (b) localização em áreas e em ecossistemas com alta capacidade de suporte; e (c) a emissão de efluentes não deve ultrapassar a capacidade de assimilação do ambiente.

\section{Tratamento de resíduos por disposição no solo}

A forma mais antiga de disposição e depuração de esgotos e de dejetos de animais é a disposição no solo (Bernardes, 1986). Tal técnica é mencionada desde tempos anteriores ao do nascimento de Cristo, sendo praticada em Atenas e na Roma Antiga (Coraucci Filho, 1991).

A disposição de águas residuárias no solo é uma atividade essencialmente de reciclagem, inclusive para a água, viabilizando a utilização do potencial hídrico e dos nutrientes presentes nos efluentes líquidos, empregando a natureza como receptora de resíduos e geradora de riquezas. É um processo que pode ser considerado como de tratamento e aproveitamento ao mesmo tempo, tendo por objetivo a redução dos custos de tratamento, o reaproveitamento dos nutrientes contidos nas águas residuárias e nos dejetos 
BARROS, F.M. et al. Utilização de água residuária de suinocultura como fonte de nitrogênio para o solo. PUBVET, Londrina, V. 5, N. 33, Ed. 180, Art. 1212, 2011.

e o melhoramento das condições físicas e químicas do solo (Coraucci Filho et al., 1999).

O constante aumento dos custos dos fertilizantes químicos vem induzindo os produtores a diminuir a adubação mineral e aproveitar todos os recursos disponíveis na propriedade para viabilizar a produção agrícola. Dentre esses recursos está o aproveitamento dos dejetos de suínos, que têm grande potencial fertilizante (Kozen, 1983; Scherer et al., 1984).

A aplicação de dejetos de suínos no solo é justificável em virtude dos efeitos proporcionados pela matéria orgânica. Esses efeitos se dividem em: físicos, caracterizados pelas modificações na estrutura do solo, pela redução da plasticidade e da coesão, pelo aumento da capacidade de retenção de água e pela manutenção de temperaturas mais uniformes; químicos, caracterizados pelo aumento da capacidade de troca catiônica, pelo aumento do podertampão, pela formação de compostos orgânicos como quelatos e, evidentemente, como fontes de nutrientes; e biológicos, responsáveis pela intensificação das atividades microbianas e enzimáticas dos solos (Kiehl, 1985).

Segundo Kiehl (1985), a matéria orgânica contribui para que os solos ácidos possam passar a apresentar $\mathrm{pH}$ mais favorável ao desenvolvimento das plantas. A adição de material orgânico no solo em condições aeróbicas é responsável pela elevação do $\mathrm{pH}$, pois a decomposição do resíduo é de reação alcalina, pela formação de humatos alcalinos (Kiehl, 1985). Primavesi (1968) constatou que a aplicação de 40 t/ha de esterco animal foi mais efetiva em corrigir o pH do solo ácido do que a aplicação de 1t/ha de calcário. Mazur et al. (1983), utilizando composto de lixo urbano para determinar a influência da matéria orgânica no $\mathrm{pH}$ do solo, verificou que houve elevação do $\mathrm{pH}$ de 5,2 para 5,7. Konzen et al. (1997) verificaram que 55 a 60 toneladas de águas residuárias de suinocultura equivalem, com base na quantidade de nutrientes, a uma tonelada de adubo químico.

A disposição dos resíduos animais no solo pode favorecer tanto o produtor, que irá reduzir seus custos com a aplicação de fertilizantes e, 
BARROS, F.M. et al. Utilização de água residuária de suinocultura como fonte de nitrogênio para o solo. PUBVET, Londrina, V. 5, N. 33, Ed. 180, Art. 1212, 2011.

conseqüentemente, aumentar a produtividade das culturas a longo prazo, como ao meio ambiente, visto que esses estercos são altamente poluentes quando lançados diretamente em rios e lagos (Hubbard et al., 1987).

A utilização de dejetos de suínos como fertilizantes orgânicos pode contribuir para a contaminação dos recursos hídricos e do solo se as quantidades aplicadas forem superiores à capacidade do solo e das plantas em absorver os nutrientes presentes nesses resíduos. Dessa forma, poderá haver contaminação das águas superficiais pelo deflúvio, quando a capacidade de infiltração da água no solo for baixa, e a contaminação das águas subterrâneas, quando a taxa de infiltração da água no solo for elevada (Pote et al., 2001). As quantidades e as freqüências com que as dejeções animais podem ser aplicadas ao solo variam com o tipo de solo, com a natureza e com a composição dos resíduos, com as condições climáticas e com a espécie vegetal cultivada (Gianello e Ernani, 1983).

O mau uso dos dejetos de suínos pode trazer efeitos deletérios ao solo, como por exemplo, o entupimento dos macro-poros, causando o selamento superficial que dificulta a infiltração de água e a troca de gases entre a atmosfera e o solo (Loehr, 1977). Além disso, também oferece o risco de salinização do solo, poluição do solo e plantas com metais pesados e contaminação do homem e animais por agentes patogênicos proveniente dos dejetos (Matos et al., 1997). Queiroz et al. (2004) avaliando o efeito da aplicação intensiva de esterco líquido de suínos no solo $(800 \mathrm{~kg} / \mathrm{ha} / \mathrm{d}$ de DBO) cultivado com diferentes gramíneas forrageiras, verificaram que após quatro meses, houve um acúmulo de fósforo, potássio, sódio e zinco no solo, aumento da acidez e redução na saturação por bases.

\section{Mineralização do nitrogênio e contaminação de solos e águas}

O nitrogênio ocupa posição de destaque entre os elementos essenciais ao crescimento e desenvolvimento das plantas, sendo um dos macronutrientes mais caros e instáveis no solo e, por isso, é considerado, juntamente com o fósforo, o principal fator limitante à produção agrícola em solos de regiões de 
BARROS, F.M. et al. Utilização de água residuária de suinocultura como fonte de nitrogênio para o solo. PUBVET, Londrina, V. 5, N. 33, Ed. 180, Art. 1212, 2011.

clima tropical (Matos et al., 1997).

Nos países tropicais, a limitada disponibilidade de nitrogênio nos solos e os altos custos dos fertilizantes nitrogenados têm levado à utilização de resíduos como fonte de nutrientes (Vanlauwe et al., 1997). O nitrogênio é um dos principais nutrientes presentes nos dejetos de suínos, porém, é facilmente perdido por volatilização, lixiviação ou desnitrificação (Bataglia et al., 1983).

Os critérios que predizem a liberação de nitrogênio dos resíduos com base em suas características químicas podem facilitar a seleção e o manejo desses materiais. A baixa eficiência do uso de nitrogênio proveniente dos resíduos de alta qualidade é atribuída à falta de sincronismo entre a liberação de nitrogênio dos resíduos e a demanda pelas plantas, associada às perdas de nitrogênio por lixiviação (Myers et al., 1994).

Apesar de, em alguns casos, o nitrogênio apresentar-se na camada arável do solo em quantidades relativamente elevadas, aproximadamente $95 \%$ deste elemento está na forma orgânica, não disponível às plantas, sendo apenas uma pequena parte mineralizada pela microbiota do solo durante o ciclo de uma cultura (Camargo et al., 1999). Na fração sólida do dejeto de suínos, a quase totalidade do nitrogênio encontra-se fazendo parte das substancias orgânicas e, para tornar-se disponível às plantas, deve passar pelo processo de mineralização (Hoegen, 1992, citado por Scherer e Baldissera, 1994).

A mineralização do nitrogênio é o processo de transformação do nitrogênio orgânico, não assimilável pelas plantas, para a forma mineral, assimilável. Segundo Tisdale et al. (1985), a mineralização de compostos orgânicos nitrogenados ocorre, essencialmente, por meio de três reações sucessivas: aminação, amonificação e nitrificação, que levam o nitrogênio até a forma nítrica $\left(\mathrm{NO}_{3}{ }^{-}\right)$, sendo esta a forma preferencialmente absorvida pelas plantas. As reações podem ser descritas da seguinte maneira (Dias et al., 1992). 
BARROS, F.M. et al. Utilização de água residuária de suinocultura como fonte de nitrogênio para o solo. PUBVET, Londrina, V. 5, N. 33, Ed. 180, Art. 1212, 2011.

\section{Aminação}

Proteínas + compostos afins digestão enzimática $\underset{R}{\longrightarrow}-\mathrm{NH}_{2}+\mathrm{CO}_{2}+$ energia + outros produtos

Amonificação

$$
\begin{array}{ll}
\mathrm{R}-\mathrm{NH} 2+\mathrm{H}_{2} \mathrm{O} & \stackrel{\text { hidrólise enzimática }}{\longrightarrow} \mathrm{NH}_{3}+\mathrm{R}+\mathrm{OH}+\text { energia } \\
2 \mathrm{NH}_{3}+\mathrm{H}_{2} \mathrm{CO}_{3} \longrightarrow\left(\left(\mathrm{NH}_{4}\right)_{2} \mathrm{CO}_{3} \longrightarrow 2 \mathrm{NH}_{4}^{+}+\mathrm{CO}_{3}{ }^{2-}\right.
\end{array}
$$

Nitrificação

$$
\begin{aligned}
& 2 \mathrm{NH}_{4}^{+}+2 \mathrm{O}_{2} \underset{\text { Oxidação enzimática }}{\stackrel{\text { Nitrossomonas }}{\stackrel{\text { Oxidação enzimática }}{\stackrel{\text { Nitrobacter }}{\longrightarrow}} 2 \mathrm{NO}_{2}^{-}+2 \mathrm{H}_{2} \mathrm{O}}+4 \mathrm{H}^{+}} \\
& 2 \mathrm{NO}_{2}^{-}+\mathrm{O}_{2}+\text { energia }
\end{aligned}
$$

Tanto a aminação quanto a amonificação são promovidas por microrganismos heterotróficos, que requerem carbono como fonte de energia, enquanto a nitrificação é executada por microrganismos autotróficos, que obtém energia pela oxidação de sais inorgânicos e a carboxilação, a partir do $\mathrm{CO}_{2}$ do ar (Tisdale et al., 1985). Com a mineralização do material orgânico, o nitrogênio é convertido da forma orgânica para formas mais móveis e solúveis. Em ambiente aeróbio, o nitrogênio orgânico é primeiramente transformado em amônio, posteriormente, em nitrito e finalmente nitrato. Em estudo de incubação aeróbica, Reddy et al. (1979) observaram que 50\% do nitrogênio orgânico nos dejetos sólidos de suínos foi mineralizado num período de três semanas.

A mineralização do nitrogênio é influenciada, entre outros fatores, pela temperatura e pelo conteúdo de água do meio. De modo geral, o aumento da temperatura acelera as reações químicas e o metabolismo dos microrganismos (Serrano, 1997). A taxa de mineralização é alta quando a temperatura está na 
BARROS, F.M. et al. Utilização de água residuária de suinocultura como fonte de nitrogênio para o solo. PUBVET, Londrina, V. 5, N. 33, Ed. 180, Art. 1212, 2011.

faixa de 30 a $35^{\circ} \mathrm{C}$ e menor para temperaturas acima ou abaixo desses valores (Dias et al., 1992). Stanford e Epstein (1974) mostraram que a mineralização do nitrogênio diminui com a redução do conteúdo de água no solo, considerando conteúdos de água no solo inferiores à capacidade de campo. Conteúdo de água no solo acima da capacidade de campo também proporciona diminuição na taxa de mineralização do nitrogênio devido à falta do oxigênio necessário às reações de mineralização.

Durante a mineralização do nitrogênio orgânico do solo, os seus distintos componentes são transformados, em taxas variáveis, em nitrogênio inorgânico, podendo ser acumulados em função do seu elevado grau de recalcitrância e resistência ao ataque microbiano (Janssen, 1996). O nitrogênio das frações mais lábeis é liberado nos períodos iniciais do processo de mineralização e a estimativa da taxa de sua mineralização pode ser usada para ajustar as recomendações de adubação nitrogenada (Mengel, 1996). Do ponto de vista prático, tem-se observado que o potencial e a respectiva taxa de mineralização podem ser utilizados na predição da disponibilidade de nitrogênio às plantas, em determinado período de tempo.

O potencial de mineralização de nitrogênio orgânico do solo é definido como a fração presente no nitrogênio orgânico susceptível à mineralização, pressupondo que a mineralização seja descrita por uma cinética de primeira ordem (Stanford e Smith, 1972).

A dose de aplicação de resíduos orgânicos no solo pode ser determinada com base na concentração do nutriente presente em maior concentração que, normalmente, é o nitrogênio. A tomada do nitrogênio como referencial para estabelecimento da taxa de aplicação recomendável está respaldada nos riscos que se tem de contaminação de águas subterrâneas com nitrato, um ânion de grande mobilidade no solo (Matos, 2003). Considerando-se que ânions $\mathrm{NO}_{3}{ }^{-}$ são pouco adsorvidos em solos eletronegativos, eles tendem a ser carreados com águas de escoamento superficial ou lixiviados no perfil do solo (Matos, 2004).

A lixiviação de nitratos no solo pode alcançar grande magnitude se este 
BARROS, F.M. et al. Utilização de água residuária de suinocultura como fonte de nitrogênio para o solo. PUBVET, Londrina, V. 5, N. 33, Ed. 180, Art. 1212, 2011.

ânion estiver presente no solo em quantidades acima da capacidade de absorção pela cultura e quando a irrigação ou chuva exceder a capacidade de armazenagem de água do solo. Nesse caso, em razão de sua alta solubilidade em água, o nitrato deve acompanhar a água de recarga dos aqüíferos subterrâneos, trazendo sérios riscos sanitários para a população que se utiliza dessas águas para dessedentação (Muchovej e Rechcigl, 1994; Owens, 1994). Oliveira (1993) cita que a aplicação de ARS por vários anos seguidos eleva as concentrações de nitrato a níveis dez vezes superiores ao normal nas águas subterrâneas.

Com o crescente uso de fertilizantes nitrogenados na agricultura, nos últimos 50 anos, tem se percebido marcante aumento da concentração de $\mathrm{NO}_{3}{ }^{-}$ nas águas superficiais e subsuperficiais. Têm sido verificadas perdas por escoamento superficial da ordem de 25 a 50\% do nitrogênio aplicado na forma de dejeto animal. Dessa forma, em rios que drenem áreas intensivamente exploradas com agricultura ou pecuária, principalmente em épocas secas, em razão da menor diluição na água, a concentração de nitrato pode, freqüentemente, exceder $100 \mathrm{mg} / \mathrm{L}$, sendo que em áreas que não estejam poluídas, a concentração é inferior a $5 \mathrm{mg} / \mathrm{L}$ (Queiroz, 2000).

MATOS et al. (2004) objetivando avaliar a mobilidade do nitrato no perfil do solo, em rampas cultivadas com forrageiras, no tratamento por escoamento superficial de ARS, verificaram maior concentração de nitrato no tratamento que recebeu ARS do que no solo testemunha, sendo as maiores concentrações detectadas abaixo da camada de maior concentração radicular, $(20-30 \mathrm{~cm})$ tornando-se dessa forma, mais susceptível à lixiviação profunda.

\section{Modelos de predição da mineralização do nitrogênio}

Dentre as preocupações com o uso de dejetos de suínos em áreas agrícolas está aquela relativa à mineralização do nitrogênio orgânico presente no dejeto e a conseqüente possibilidade de contaminação das águas (Molina e Matiazzo, 2003).

Segundo Broadbent (1986), a mineralização do nitrogênio orgânico é 
BARROS, F.M. et al. Utilização de água residuária de suinocultura como fonte de nitrogênio para o solo. PUBVET, Londrina, V. 5, N. 33, Ed. 180, Art. 1212, 2011.

inquestionavelmente influenciada por fatores ambientais como temperatura e umidade do solo e por características do solo. A descrição do processo de mineralização em termos quantitativos requer equações com muitas variáveis, algumas das quais que não podem ser prontamente medidas e que podem variar imprevisivelmente. O nitrogênio nos solos, ao contrário dos demais nutrientes, passa por freqüentes transformações, dificultando, assim, uma avaliação precisa da sua disponibilidade.

Avaliar a possível relação entre uma variável dependente e uma ou mais variáveis independentes é uma das tarefas mais comuns em análises estatísticas. Para isso, podem ser utilizados modelos de regressão, que representem tentativas de descrição matemática de um evento natural. No caso da mineralização do nitrogênio, o propósito principal do modelo é obter dados quantitativos para recomendação da adição do nitrogênio ao solo (Tanji, 1982). No estudo da mineralização do nitrogênio em solos é importante conhecer o modelo estatístico que descreve este processo em função do tempo. A relação entre as variáveis envolvidas neste processo, geralmente, é descrita por modelos não lineares, destacando-se os modelos exponenciais (Pereira, 2003).

O primeiro estudo sobre a mineralização do nitrogênio foi feito por Stanford e Smith (1972), que usou um modelo exponencial simples (Equação 1) no qual a concentração de nitrogênio potencialmente mineralizável é decomposto na razão proporcional a sua concentração.

Equação 1: $\quad \mathrm{N}_{\mathrm{m}}=\mathrm{N}_{0}\left(1-e^{-k t}\right)$

em que:

$\mathrm{N}_{\mathrm{m}}$ = concentração de nitrogênio mineralizado em determinado tempo $\left(\mathrm{mg} \cdot \mathrm{kg}^{1}\right)$;

$\mathrm{N}_{0}=$ concentração de nitrogênio potencialmente mineralizável no solo $\left(\mathrm{mg} \cdot \mathrm{kg}^{-1}\right)$;

$\mathrm{K}=$ constante de mineralização $\left(\mathrm{dia}^{-1}\right)$;

$\mathrm{T}$ = tempo decorrido após o início da incubação (dia).

Marion et al. (1981) propuseram um modelo semelhante ao proposto por 
BARROS, F.M. et al. Utilização de água residuária de suinocultura como fonte de nitrogênio para o solo. PUBVET, Londrina, V. 5, N. 33, Ed. 180, Art. 1212, 2011.

Stanford e Smith (1972), acrescentando apenas a constante "c" como expoente do tempo (Equação 2).

Equação 2: $\quad \mathrm{N}_{\mathrm{m}}=\mathrm{N}_{0}\left(1-e^{-k t^{c}}\right)$

Conhecendo-se os valores de $\mathrm{N}_{0}$ e k para determinado solo, pode-se prever o efeito de certas práticas culturais sobre a dinâmica do nitrogênio com maior probabilidade de acerto. Em solos com $\mathrm{N}_{0}$ e $\mathrm{k}$ altos, a prática da adubação verde, por exemplo, pode ser pouco efetiva, pois se adicionaria ao solo uma grande quantidade de nitrogênio mineralizável em curto prazo, quando o problema é o suprimento de nitrogênio em longo prazo (Santos, 2001). Para essas condições, a incorporação de material com mais alta relação carbono/nitrogênio $(C / N)$ possivelmente não iria provocar imobilização de nitrogênio, podendo ser essa opção adotada no caso do solo com ARS (Parentoni et al., 1988).

Quanto maior a constante $k$, mais decrescente será a taxa de mineralização do nitrogênio orgânico ao longo do tempo, com a maior parte do nitrogênio orgânico sendo mineralizado nas semanas iniciais de incubação. Valores elevados de k sugerem que a maior parte do nitrogênio passível de se tornar disponível à cultura seja originado de compostos de rápida mineralização (proteínas, aminoácidos etc.) (Parentoni et al., 1988).

Broadbent (1986) propôs o modelo potencial, descrito na Equação 3, para predizer os valores de nitrogênio mineralizado com o tempo.

\section{Equação 3: $\quad \mathbf{N}_{m}=A t^{b}$}

em que:

$$
\begin{aligned}
& A=\text { constante de mineralização }\left(\mathrm{mg} \cdot \mathrm{kg}^{-1} \cdot \mathrm{dia}^{-\mathrm{b}}\right) ; \\
& \mathrm{b}=\text { constante; } \\
& \mathrm{t}=\text { tempo (dia). }
\end{aligned}
$$


BARROS, F.M. et al. Utilização de água residuária de suinocultura como fonte de nitrogênio para o solo. PUBVET, Londrina, V. 5, N. 33, Ed. 180, Art. 1212, 2011.

Em estudos realizados por Pereira et al. (2003), o modelo de Marion et al. (1981) foi o que melhor descreveu o processo de mineralização do nitrogênio orgânico no solo.

A metodologia descrita por Stanford e Smith (1972) para obtenção dos parâmetros da Equação 1, na qual também se baseiam os outros modelos (Equações 2 e 3), propõe a incubação de solo em colunas, em condição aeróbia a $35^{\circ} \mathrm{C}$, e, ao final de 2, 4, 8, 16 e 32 semanas, os solos das colunas são lixiviados com $\mathrm{CaCl}_{2}$ 0,01mol/L e solução nutritiva desprovida de nitrogênio. Nesses lixiviados são determinadas a concentração de $\mathrm{NH}_{4}+$ e de $\mathrm{NO}_{3}{ }^{-}+\mathrm{NO}_{2}{ }^{-}$. Uma limitação considerável que ocorre nesta metodologia é a remoção de nitrogênio orgânico solúvel durante o processo de lixiviação. Esta forma solúvel facilmente mineralizável não é contabilizada no processo de mineralização, gerando assim subestimativas do nitrogênio potencialmente mineralizável (Camargo, 1996).

\section{CONSIDERAÇÕES FINAIS}

Na suinocultura, os dejetos, a água desperdiçada em bebedouros e a água de lavagem das instalações geram grandes volumes de águas residuárias, as quais são fontes potenciais de poluição ambiental. A disposição de águas residuárias provenientes de suinocultura (ARS) no solo é uma atividade essencialmente de reciclagem que viabiliza a utilização do potencial hídrico e dos nutrientes presentes nos efluentes. Porém, a utilização desta como fertilizante orgânico pode contribuir para a contaminação dos recursos hídricos e do solo se as quantidades aplicadas forem superiores à capacidade do solo e das plantas em absorver os nutrientes presentes nesses resíduos.

A dose de aplicação do resíduo pode ser determinada com base na concentração do nutriente presente em maior concentração que, normalmente, é o nitrogênio. Os critérios que predizem a liberação de nitrogênio dos resíduos com base em suas características químicas podem facilitar a seleção e o manejo desses materiais. A baixa eficiência do uso de nitrogênio proveniente 
BARROS, F.M. et al. Utilização de água residuária de suinocultura como fonte de nitrogênio para o solo. PUBVET, Londrina, V. 5, N. 33, Ed. 180, Art. 1212, 2011.

dos resíduos orgânicos é atribuída à falta de sincronismo entre a liberação do nitrogênio dos resíduos e a demanda pelas plantas, associada às perdas por lixiviação. A sincronia não necessariamente aumenta os rendimentos das plantas em curto prazo, mas pode reduzir as perdas de nitrogênio e melhorar a fertilidade do solo, em longo prazo.

\section{REFERÊNCIAS BIBLIOGRÁFICAS}

ALVES, G.D.; SAMPAIO, E. V. S. B.; SALCEDO, I. M.; SILVA, V. M. 1999. Potencial de mineralização de $\mathrm{N}$ em vinte solos de Pernanbuco. Revista Brasileira de Ciência do Solo, 23:245-256.

NUALPEC. 2003. Anuário da Pecuária Brasileira - FNP-Consultoria e Comércio. São Paulo: Ed. Argos Comunicação. 400p.

BATAGLIA, O.C.; BERTON, R.S.; CAMARGO, O.A.; VALADARES, J.M.A.S. 1983. Resíduos orgânicos como fonte de nitrogênio para capim braquiária. Revista Brasileira de Ciência do Solo, 7:277-84.

BERNARDES, R.S. 1986. Estabilização de poluentes por disposição no solo. Revista Dae, 145:48-129.

BLEY JUNIOR, C. 1997. Instalações para tratamento de dejetos. In: Ciclo de palestras sobre dejetos de suínos, manejo e utilização, do Sudeste Goiano, Rio Verde. Anais, ESUCARV. p. 48-68.

BRANDÃO, V.S. 1999. Tratamento de águas residuárias de suinocultura utilizando filtros orgânicos. Dissertação - Mestrado em Engenharia Agrícola - Universidade Federal de Viçosa. Viçosa: UFV, 65p.

BROADBENT, F.E. 1986. Empirical modeling of soil nitrogen mineralization. Soil Science, $141: 208-213$

CAMARGO, F.A.O. 1996. Fracionamento e dinâmica do nitrogênio orgânico em solos do Rio Grande do Sul. Tese de Doutorado - Universidade Federal do Rio Grande do Sul. Porto Alegre: UFRGS, 152p.

CAMARGO, F.A.O.; GIANELLO, C.; TEDESCO, M.J.; VIDOR, C. 1999. Nitrogênio orgânico do solo. In: Santos, G.A. e Camargo, F.A.O. (Eds.). Fundamentos da matéria orgânica do solo: ecossistemas tropicais e sub-tropicais. Porto Alegre: Gênesis. p.117-138.

CAMPBELL, A.C.; JAME, Y.W.; AKINREMI, O.O.; CABRERA, M.L. 1995. Adapting the potentially mineralizable $\mathrm{n}$ concept for the prediction of fertilizer $\mathrm{n}$ requirements. Fertilizer Research., 42:61-75.

CORAUCCI FILHO, B. 1991. Tratamento de esgotos domésticos no solo pelo método do escoamento superficial. Tese de Doutorado - Universidade de São Paulo. São Paulo: USP. $400 \mathrm{p}$.

DIAS, L.E.; BARROS, N.F.; FRANCO, A.A. 1992. Curso de especialização por tutoria à distância: módulo 6- nitrogênio no solo. Brasília: Associação Brasileira de Educação Agrícola Superior. 82p.

DRUMOND, L.C.D. 2003. Aplicação de água residuária de suinocultura por aspersão em malha: desempenho hidráulico do sistema e produção de capim tifton 85. Tese de Doutorado em Produção Vegetal - Universidade Estadual Paulista. Jaboticabal: UNESP. 120p. 
GIANELLO, C.; ERNANI, P.R. 1983. Rendimento de matéria seca de milho e alterações na composição química do solo pela incorporação de quantidades crescentes de cama de frangos, em casa de vegetação. Revista Brasileira de Ciência do Solo, 7:285-90.

HUBBARD, R.K.; THOMAS, D.L.; LEONARD, R.A. et al. 1987. Surface runoff and shallow ground water quality as affected by center pivot applied dairy cattle wastes. Transactions of the ASAE, 30(2):430- 437.

JANSSEN, B.H. 1986. Nitrogen mineralization in relation to C: $\mathrm{N}$ ratio and decomposability of organic materials. Plant Soil, 1881:39-45.

KIEHL, e.j. 1985. Fertilizantes orgânicos. Piracicaba: Agronômica Ceres. 492p.

KONZEN, E.A. 2002. Aproveitamento do adubo líquido da suinocultura na produção agropecuária. In: congresso nacional de irrigação e drenagem. Anais. Uberlândia: ABID.

KOZEN, E.A.; Pereira Filho, I.A.; Bahia Filho, A.C.F. e Pereira, F.A. 1997. Manejo do esterco líquido de suínos e sua utilização na adubação do milho. Circular Técnica, 25. Sete Lagoas: EMBRAPA-CNPMS. 31p.

LOEHR, R.C. 1977. Pollution control for agriculture. New York: Academic Press. 383p.

MARRIEL, I.E.; KOZEN, E.A; ALVARENGA, R.C.; SANTOS, H.L. 1987. Tratamento e utilização de resíduos orgânicos. Informe Agropecuário, 13(147): 24-36.

MARION, G.M., KUMMEROW, J.; MILLER, P.C. 1981. Predicting nitrogen mineralization in chaparral soils. Soil Science Society of America Journal, 45:956-961.

MATOS, A.T. 2004. Tratamento e aproveitamento agrícola de resíduos sólidos. Caderno Didático n.37. Viçosa: AEAGRI. 136p.

MATOS, A.T. 2003. Aproveitamento de efluentes líquidos domésticos e agroindustriais na agricultura. In: Encontro de preservação de mananciais da zona da mineira, Viçosa. Anais. ABES/MG. p.25-79.

MATOS, A.T.; SEDIYAMA, M.A.N.; FREITAS, S.P.; VIDIGAL, S.M.; GARCIA, N.C.P. 1997. Características químicas e microbiológicas do solo influenciadas pela aplicação de dejeto líquido de suínos. Revista Ceres, 44(254): 399-410.

MAZUR, N.; SANTOS, G.A.; VELLOSO, A.C.X. 1983. Efeito do composto de resíduo urbano no pH e alumínio trocável em solo ácido. Revista Brasileira de Ciência do Solo, 7: 157-159.

MENGEL, K. 1996. Turnover of organic nitrogen in soils and its availability to crops. Plant Soil, The Hage, 181:83-93.

MERTEN, G.H.; MINELLA, J.L. 2002. Qualidade da água em bacias hidrográficas rurais: um desafio atual para a sobrevivência futura. Agroecologia e Desenvolvimento Rural Sustentável, 3(4):33-38.

MOLINA, M.V.; MATIAZZO, M.E. 2003. Nitrogênio inorgânico em solo cinco anos após a aplicação de biossólido. In: Congresso Brasileiro de Ciência do Solo, Ribeirão Preto. Anais, CBCS.

MUCHOVEJ, R.M.C; RECHCIGL, J.E. 1994. Impact of nitrogen fertilization of pastures and turfgrasses on water quality. In: Lal, R. e Stewart, B.A. (Ed.). Soil processes and water quality. Boca Raton: Lewis Publishers. p.91-135.

MYERS, R.J.K.; PALM, C.A.; CUEVAS, E.; GUNATILLE, K.E.; BROSSARD, I.U.N. 1994. The synchronisations of mineralisation and plant nutrient demand. In: WOOMER, P.L. e SWIFT, M.J. (Eds.). The biological management of tropical soil fertility. New York: John Wiley and Sons. p. 81-116.

NOGUEIRA, C.P.; SILVA, I.J.O. 2006. Aplicação de águas residuárias de suinocultura na irrigação. Thesis, 6:18-29. 
OLIVEIRA, P.A.V. 1993. Manual de manejo e utilização dos dejetos de suínos. Concórdia: EMBRAPA-CNPSA.188p.

OWENS, L.B. 1994. Impacts of soil $n$ management on the quality of surface and subsurface water. In: Lal, R. e Stewart, B.A. (Ed.). Soil processes and water quality. Boca Raton: Lewis Publishers. p.137-162.

PARENTONI, S.N.; FRANÇA, G.E.; BAHIA FILHO, A.F.C. 1988. Avaliação dos conceitos de quantidade e intensidade de mineralização de nitrogênio para trinta solos do Rio Grande do Sul. Revista Brasileira de Ciência do Solo, 12:225-229.

PERDOMO, C.C. 1995. Uso racional da água no manejo de dejetos suínos. In: seminário mineiro sobre manejo e utilização de dejetos de suínos, Ponte Nova. Anais, Ponte Nova: EPAMIG/CRZM. p. 88- 110.

PEREIRA, J.M. 2003. Predição do índice de mineralização do nitrogênio em solos através da comparação de modelos não lineares. In: Seagro, Lavras. Anais, Lavras.

POTE, D.H.; REED, B.A.; DANIEL, T.C.; NICHOLS, D.J.; MOORE, P.A.; EDWARDS, D.R. 2001. Water-quality effects of infiltration rate and manure application rate for soils receiving swine manure. Journal Soil and Water Conservation, 56(1): 32-37.

PRIMAVESI, A. 1968. Organic matter and soil productivity in the tropics and subtropics. In: Organic matter and soil fertility, New York: John Wiley and Sons, p.653-596.

QUEIROZ, F.M. 2000. Avaliação de gramíneas forrageiras para o tratamento de águas residuárias da suinocultura. Dissertação - Mestrado em Engenharia Agrícola Universidade Federal de Viçosa. Viçosa: UFV, 91p.

REDDY, K.R.; KHALEEL, R.; OVERCASH, M.R.; WESTERMAN, P.W. 1979. A nonpoint source model for land areas receiving animal waste: II. Ammonia volatilization. Transactions of the ASAE, 22(6):1398-1405.

SANTOS, C.A.A. 2001. Potencial de mineralização e disponibilidade de nitrogênio de solos. Dissertação - Mestrado em Engenharia Agrícola - Universidade Federal de Viçosa. Viçosa: UFV, 59p.

SCHERER, E.E.; BALDISSERA, I.T. 1994. Aproveitamento dos dejetos de suínos como fertilizantes. In: Dia de campo sobre manejo e utilização de dejetos de suínos, Concórdia. Anais, Concórdia: EMBRAPA-CNPSA. p.47.

SERRANO, M.I.P. 1997. Mineralização, absorção e lixiviação de nitrogênio em povoamentos de Eucalyptus grands sob cultivo mínimo e intensivo do solo. Dissertação - Mestrado Escola Superior de Agronomia Luiz de Queiroz. Piracicaba: ESALQ, 1997. 86p.

STANFORD, G.; EPSTEIN, L. 1974. Nitrogen mineralization - water relations in soils. Soil Science Society of America Proceedings, 38: 103-106.

STANFORD, G.; SMITH, S.J. 1972. Nitrogen mineralization potencial of soil. Proc. Soil Soc. Am. J., 36:465-472.

SILVA, E.T.; MAGALHÃES, C.S. 2001. Controle de poluição de atividades pecuárias. Informe Agropecuário, 22(210):62-76.

TISDALE, S.; NELSON, W.; BEATON, J.D. 1985. Soil fertilitey and fertilies. 4ed. New York: Macnillan, 754p.

TANJI, K.K. 1982. Economical implications of controls on nitrogen fertilizer use. In: Stevenson, F.J. Nitrogen in agricultural soils. Madison: ASA/SSSA, p.721-772.

VANLAUWE, J.D.; SANGINGA, N.; MERCKX, R. 1997. Residue quality and decomposition: an unsteady relationship? In: Cadisch, G. e Giller, K.E. Driven by nature- pant letter quality and decompositions. Wallingford: CAB International, p.157-166. 
VIEIRA. L. 1997. Produção de minhocas em dejetos suínos estabilizados e valor nutritivo da farinha de minhoca para suínos. Dissertação - Mestrado em Zootecnia - Universidade Federal de Viçosa. Viçosa: UFV, 56p. 